\title{
Studies on optimization of radiation protection for patients in diagnostic radiology
}

\author{
Z. WEI*, X. ZONG**, Z. QIANG***, Q. ZHANG*, Y. WU****, \\ W. LI*, K. LI*, L. WEI*
}

(Manuscrit reçu le 7 avril 1993)

ABSTRACT For the exposure of patients in diagnostic radiology, individual dose limit does not apply, but optimization of radiological protection may play a major role. This project has been carried out with the purpose of improving the protection of patients in medical diagnostic radiology in China utilizing the principles of optimization. Taking Sichuan, Shandong and Beijing as surveyed areas, we investigated the present situation of the protection of patients. In the survey, the patient doses were classified into practical dose, justified dose and optimized dose to evaluate the influences of managerial and equipment factors separately.

The results show that there are some urgent protection problems in $X$-ray protection to be solved in the surveyed regions. This paper, however, points out that the prospects of reducing patient doses are encouraging provided that appropriate measures are adopted. For instance, taking proper managerial measures without radical change of existing equipments may reduce patient doses in chest fluoroscopy and radiography by $\mathbf{4 0} \%$ and $18 \%$ respectively; refitting some equipment may reduce the doses by $82.4 \%$ in chest fluoroscospy, $66 \%$ in chest radiography, and $80 \%$ in barium meal examination of the gastrointestinal (GI) tract. Using chest radiography instead of fluoroscopy supplemented by other protection measures may reduce the doses by $91.7 \%$. Optimization analysis shows that adoption of the above measures conforms to the principle of optimization of radiation protection.

RÉSUMÉ Si, dans le cas du radiodiagnostic, les limites de dose individuelles ne s'appliquent pas à l'exposition des patients, l'optimisation de la radioprotection peut, par contre, jouer un rôle important. L'utilisation du principe d'optimisation a guidé ce projet visant à améliorer, en Chine, la protection des patients lors de la pratique du radiodiagnostic médical. Notre enquête, réalisée dans les régions de Sichuan, Shandong et Pékin (Chine), a évalué la situation actuelle de la protection des patients. Les doses aux patients ont été classées en dose réelle, dose justifiée et dose optimisée afin d'évaluer séparément l'influence des facteurs de

\footnotetext{
* Laboratory of industrial hygiene, Ministry of public health, 2 Xinkang street, PO Box 8018, Beijing 100088, P.R. China.

** Institute of radiation medicine, Shandong Academy of medical sciences, Jinan 250001, P.R. China.

*** Sichuan Institute of radiation health protection, Chengdu 610041, P.R. China.

**** Beijing Institute of radiation bealth protection, Beijing 100013, P.R. China.
} 
gestion et d'équipement. Les résultats démontrent l'urgente nécessité de résoudre un certain nombre de problèmes dans la protection contre les rayons $X$. Cet article indique, toutefois, que les perspectives de réduction des doses sont encourageantes si des dispositions adéquates sont adoptées. Ainsi, une bonne gestion, sans changement radical des équipements actuels, peut réduire les doses en fluoroscopie et radiographie pulmonaires, respectivement, de 40 à $18 \%$, la révision de certains équipements de 82,4 et $66 \%$, et de $80 \%$ dans les examens du tractus gastrointestinal avec repas baryté. L'utilisation de la radiographie pulmonaire au lieu de la fluoroscopie associée à d'autres dispositions peut aboutir à une réduction de $91,7 \%$. Une analyse de cette optimisation montre que ces dispositions sont conformes au principe d'optimisation de la radioprotection.

\section{Introduction}

As stated in ICRP Publication 60 [3], the system of radiation protection in medical radiology consists of justification of a practice involving radiation exposure, optimization of radiation protection and individual dose limits. This paper deals with a study on optimization of radiation protection for patients in diagnostic radiology, based on the present status in China, and considers the use of dose constraint with the view of finding the best way to improve the present status of patient protection in diagnostic radiology in this country $[4,5]$.

For this purpose, we carried out surveys in Beijing, Sichuan and Shandong areas on clinical chest fluoroscopy, mass chest fluoroscopy, chest radiography, and digestive tract examinations, which are widely used and which present more protection problems.

\section{Survey methods and results}

In the survey, the skin exposure of patients to ionizing radiation in various radiological examinations was first investigated. The dosemeter used in the survey is the calibrated TLD ( $\mathrm{LiF}$, activated by $\mathrm{Mg}, \mathrm{Cu}, \mathrm{P}$ ). In the survey, TLDs coded were attached to the incident skin surface over the 6th thoracic vertebra in chest fluoroscopy and radiography, and the 6th thoracic and 1st lumbar vertebrae in GI tract examination, respectively. After exposure, the TLD readings were made on a TLD reader. Then the conversion coefficients of skin exposure to effective dose (hereafter referred to as " $R-E$ coefficients") were determined, based on phantom experiments. Finally, the effective dose to patient for each kind of X-ray examination was estimated. The $R-E$ coefficients were first determined under definite clinical conditions. In order to make the $R-E$ coefficients applicable to $\mathrm{X}$-ray examinations with varying exposure field sizes and different tube potentials, correction of $R-E$ coefficients for field size and energy was studied. 
For optimization purposes, the patient doses were classified into three types : the practical dose, the justified dose and the optimized dose. "Practical dose" means the average dose delivered to the patient in a certain X-ray procedure in actual pratice. It includes a dose required for the purpose of obtaining sufficient diagnostic information, and additional dose resulting from X-ray machine in abnormal working conditions and under improper operation. "Justified dose" means the average dose to the patient from an X-ray machine without substantial refitting, but in normal working conditions and under correct operation. "Optimized dose" means the reduced dose to the patient after improvements made in equipment and examination techniques. Obviously, the difference between practical dose and justified dose reflects the dose to the patient possibly reduced by following rational management rules and standardized operation procedures. And the difference between practical and optimized dose reflects the patient dose reduced by using better equipment and advanced examination techniques. In this study the above three types of doses were investigated to evaluate separately the effects of management factor and equipment factor on patient dose in diagnostic radiology.

In order to determine the $R-E$ coefficients in the surveyed areas, the following experimental conditions were adopted in our study, based on the physical parameters often used in radiological practice in the respective areas (Tab. I).

TABLE I

Experimental conditions based on radiological practice in the surveyed areas Conditions expérimentales selon les pratiques radiologiques dans les régions étudiées

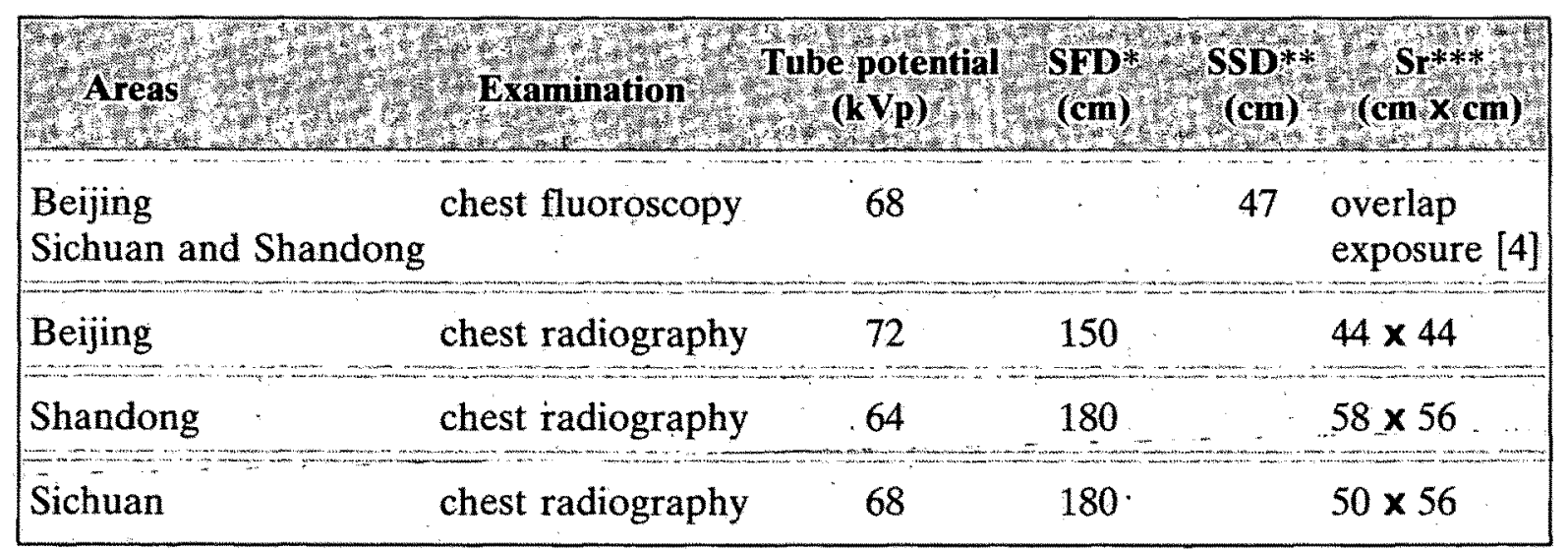

* Source-film distance.

** Source-skin distance.

*** Exposure field size.

Based on the above experimental conditions, the determined $R-E$ coefficients are as follows (Tab. II) : 
TABLE II

$R-E$ coefficients for various $X$-ray procedures

Coefficient de conversion "dose à la peau/dose efficace" $(R-E)$

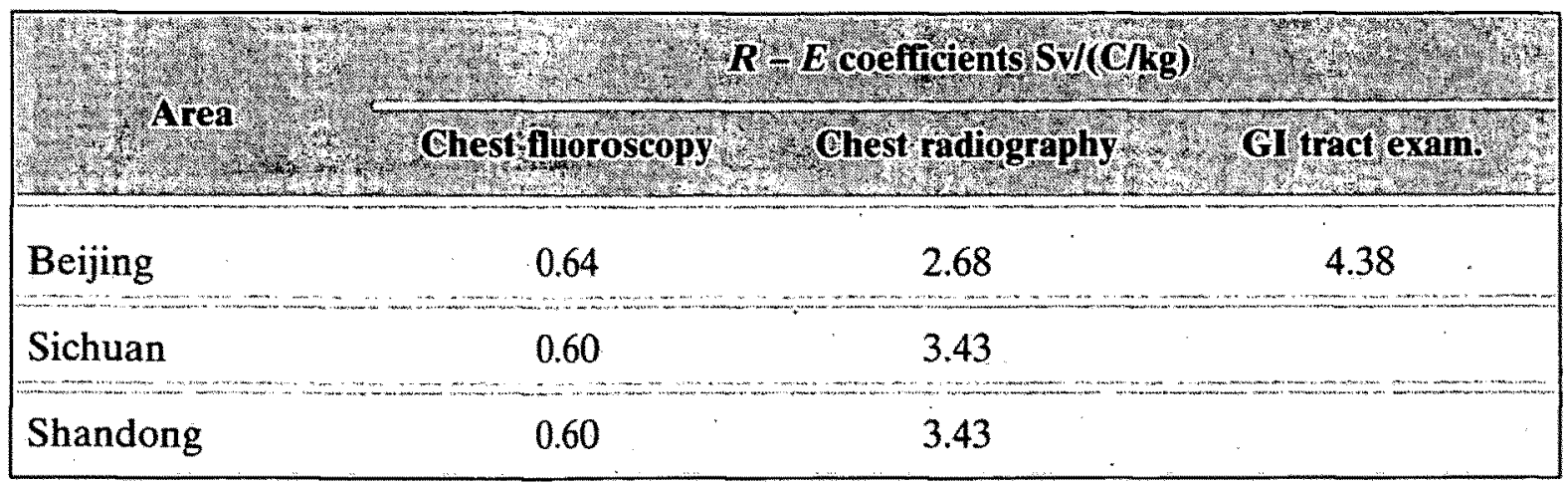

Since the tube potential (kVp), source film distance (SFD), source-skin distance (SSD) and field size (Sr) used in radiological practice in different surveyed areas are not all the same, there is discrepancy between the $R-E$ coefficients determined in different areas. Furthermore, since in the experiments we did not determine the particular conversion coefficients for mass chest fluoroscopy and GI tract examination in Sichuan and Shandong, the $R-E$ coefficients determined for Beijing are used for Sichuan and Shandong in the following dose estimation. The results of correction of $R-E$ coefficients for field size and energy are shown in Figures 1 and 2.

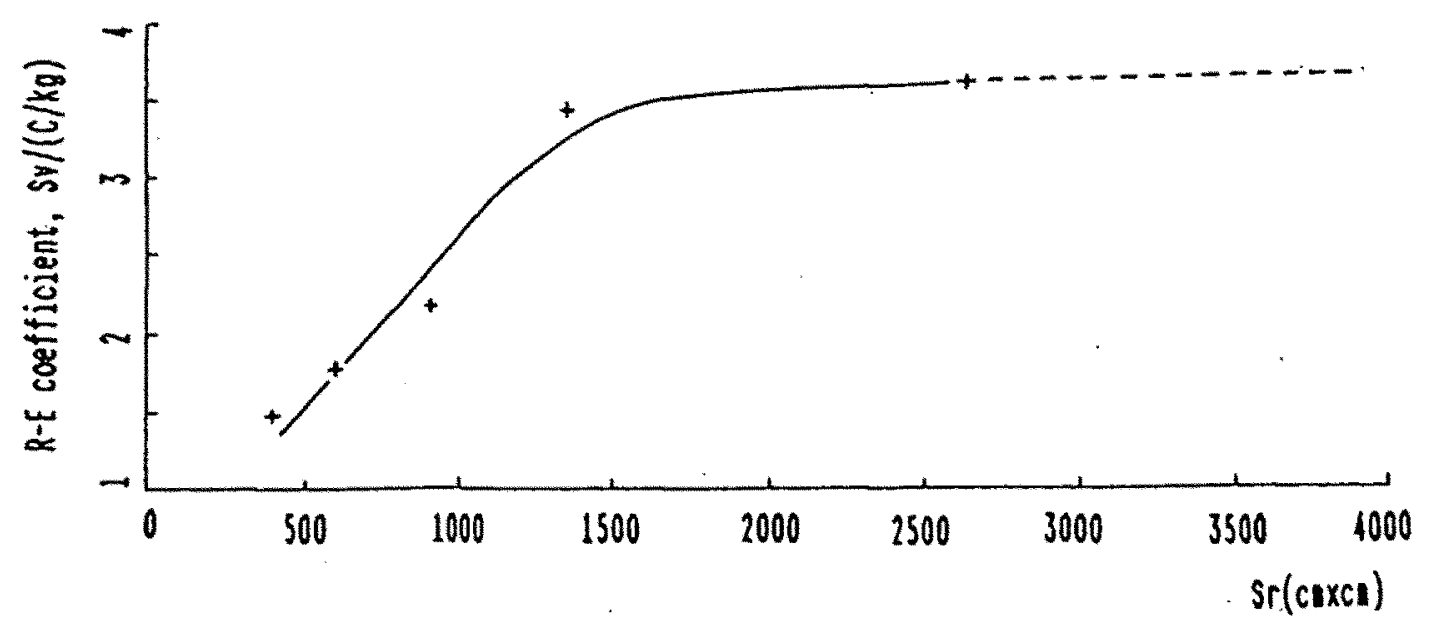

Fig. 1 - Variation of $R-E$ according to size of exposure field.

Variation de $R-E$ selon les dimensions du champ exposé.

In order to obtain the results with better representativeness, the investigation on the practical dose was conducted by using stratified random sampling procedure. First, we randomly took a sample of hospitals at different levels in each surveyed area ; and then, we randomly selected a number of patients from 
these hospitals to measure the skin exposure doses. In general, 20-50 hospitals for each surveyed area and 200-1000 cases for each kind of X-ray examination were selected. The results are shown in Table III.

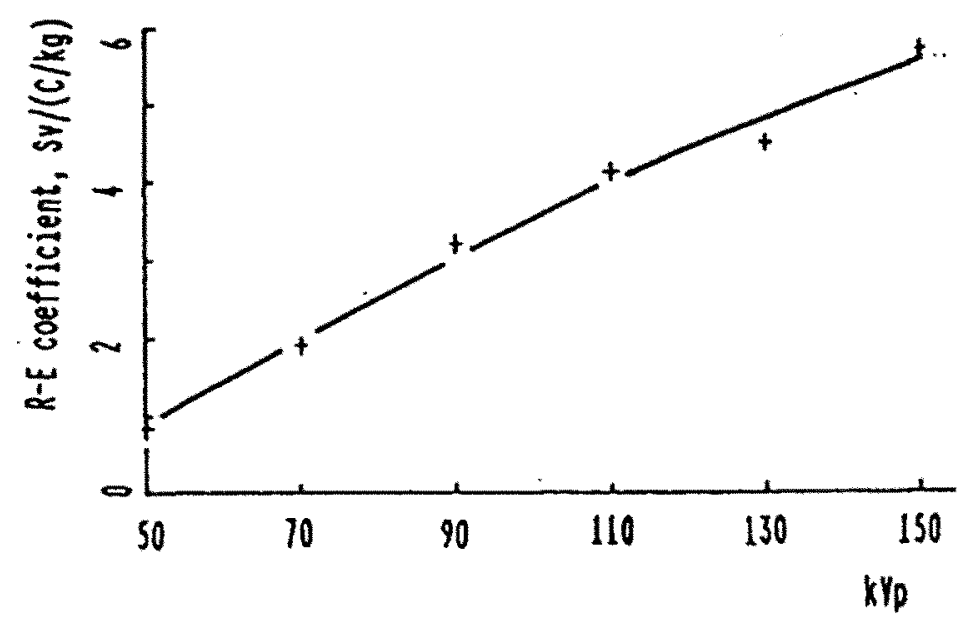

Fig. 2 - Correction of $\boldsymbol{R}-\boldsymbol{E}$ coefficients for energies.

Correction du coefficient $R-E$ en fonction de l'énergie.

TABLE III

Practical doses to patients in various $X$-ray examinations in each area Dose réelle au patients pour divers examens aux rayons $X$ dans chaque région

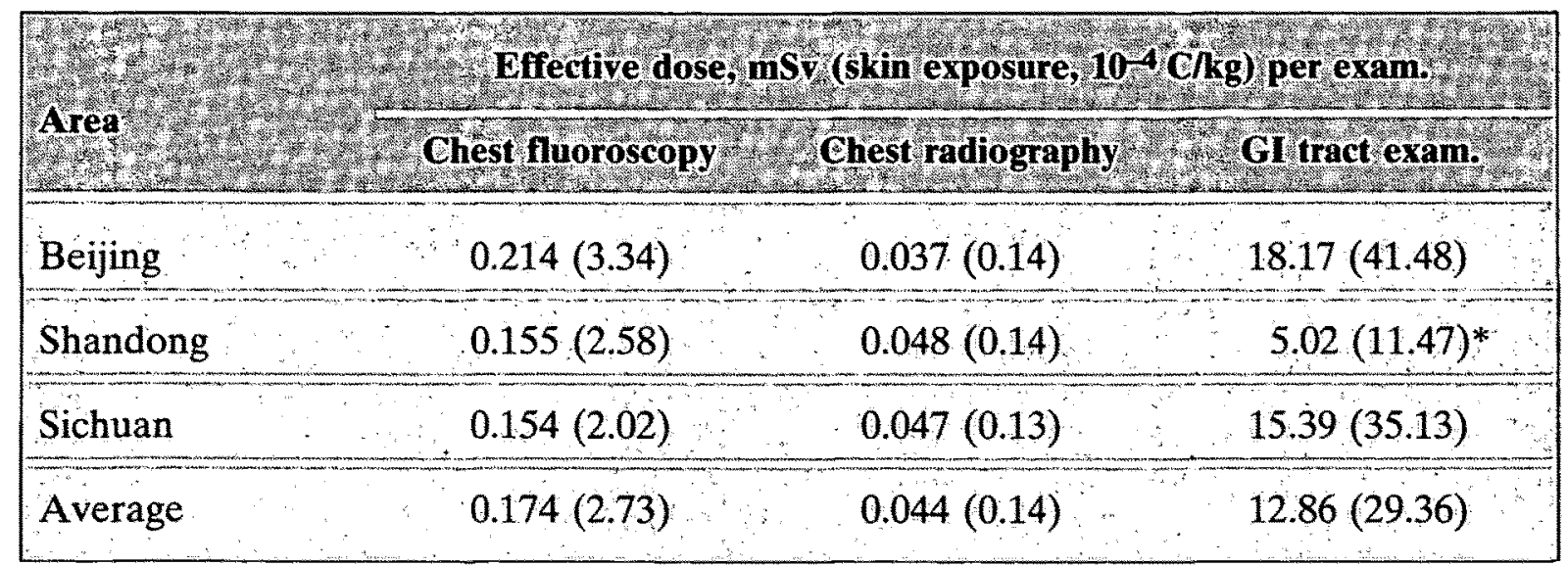

* Chiefly results of upper digestive tract examinations.

The sampling method for the investigation on justified doses was generally the same as that for investigation on practical doses. Since the performance of the X-ray machines selected and the competence of operators were strictly prescribed in the investigation on justified dose levels, and the uncertainties causing deviation of survey results diminished, the number of investigated cases for each kind of X-ray examination were slightly smaller (about 20 cases for each). The results are shown in Table IV. 
TABLE IV

Justified doses to patients in various $X$-ray examinations in surveyed areas Dose justifiée aux patients pour divers examens aux rayons $X$ dans les régions étudiées

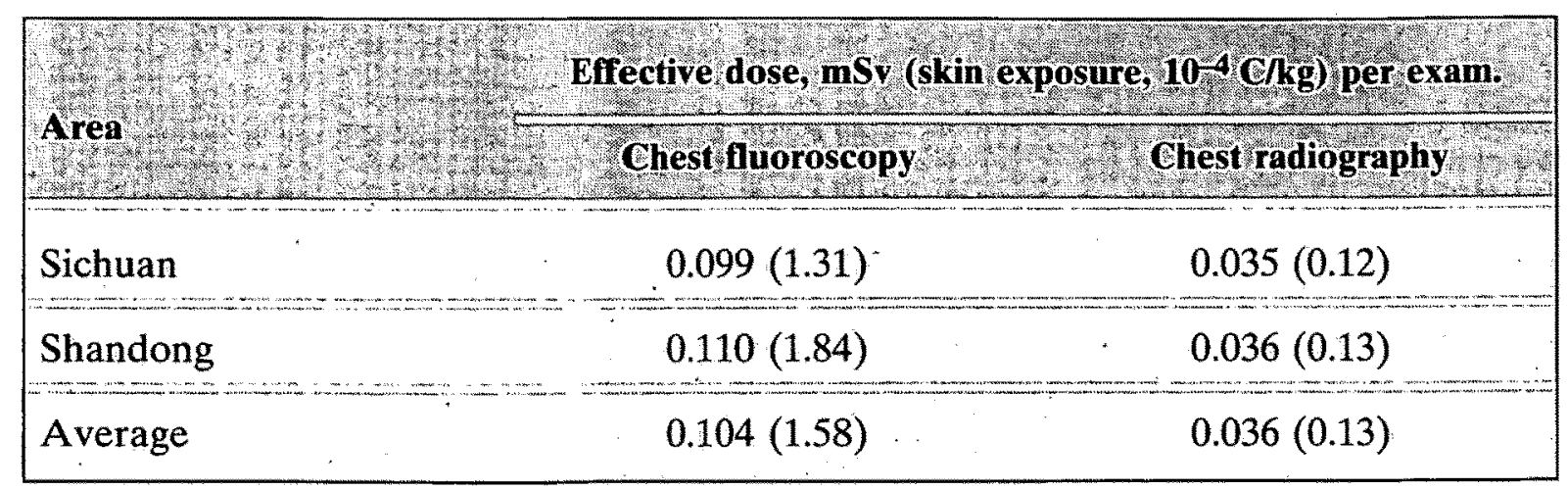

Taking the practical doses from various X-ray procedures as $100 \%$, the percentages of the justified doses from corresponding X-ray procedures have been plotted against the practical doses (Fig. 3).
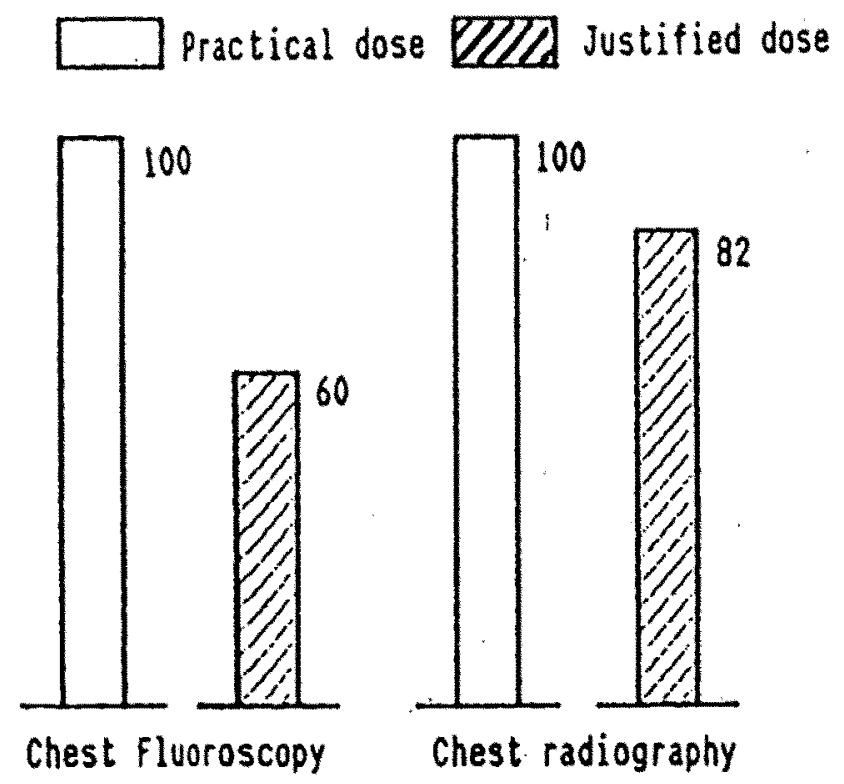

Fig. 3 - Comparison of practical dose with justified dose. Comparaison de la dose réelle et de la dose justifiée.

It can be seen from Figure 3 that the patient doses in chest fluoroscopy and chest radiography can be reduced by $40 \%$ and $18 \%$, respectively, if appropriate managerial measures are taken. 
To appraise the effectiveness of single optimization measures in reducing patient dose, we determined the reduction coefficients of patient dose by measuring doses both to patients and to a phantom for experiment. The results are given in Table $\mathrm{V}$.

TABLE V

Effects of single optimization measures on reduction of patient dose Effet d'une opération d'optimisation sur la réduction de la dose aux patients

\begin{tabular}{|c|c|c|}
\hline Examination & Optimization measures & $\begin{array}{l}\text { Reduction coefficient } \\
\text { of patient dose }\end{array}$ \\
\hline Out-patient chest fluoroscopy & $\begin{array}{l}\text { New screen replacing old aging ones } \\
\text { Simple shielding } \\
\text { Image intensifier replacing } \\
\text { fluoroscopy screen } \\
\text { Chest radiography instead of } \\
\text { chest fluoroscopy }\end{array}$ & $\begin{array}{l}0.51 \\
0.88[5] \\
0.20 \\
0.25\end{array}$ \\
\hline 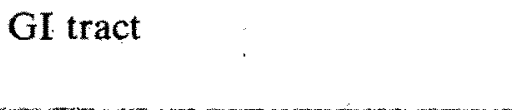 & $\begin{array}{l}\text { Image intensifier replacing } \\
\text { fluoroscopic screens }\end{array}$ & 0.20 \\
\hline Chest radiography & $\begin{array}{l}\text { Rare-earth screens replacing } \\
\quad \mathrm{CaWO}_{4} \text { screens } \\
\text { Beam limitation } \\
\text { Simple shielding } \\
100 \mathrm{kVp}^{-} \text {instead of } 70 \mathrm{kVp}\end{array}$ & $\begin{array}{l}0.43 \\
0.83 \\
0.70 \\
0.68\end{array}$ \\
\hline
\end{tabular}

* Reduction coefficient of patient dose : patient dose after taking optimization measures/dose before taking the measures.

Taking the practical doses from various $X$-ray procedures as $100 \%$, the percentages of the optimized doses from corresponding $X$-ray procedures have been plotted against the practical doses (Fig. 4).

Figure 4 shows that the patient dose in chest fluoroscopy can be reduced by $82.4 \%$ by using image intensifiers instead of conventional screens and simple shielding ; in chest X-ray fluoroscopy, the dose to the patient can be reduced by $91.7 \%$ by using radiography, rare earth screen and improving beam limitation ; in chest radiography, the dose can be decreased by $66 \%$ by using rare earth screen instead of $\mathrm{CaOW}_{4}$ screen and beam limitation ; and in GI tract examination, the dose decreased by $80 \%$ by using image intensifiers instead of conventional screens.

The above results show that although there are some problems in the protection of patients in diagnostic radiology, the reduction of patient dose is possible if appropriate protective measures in management and equipment are taken. 


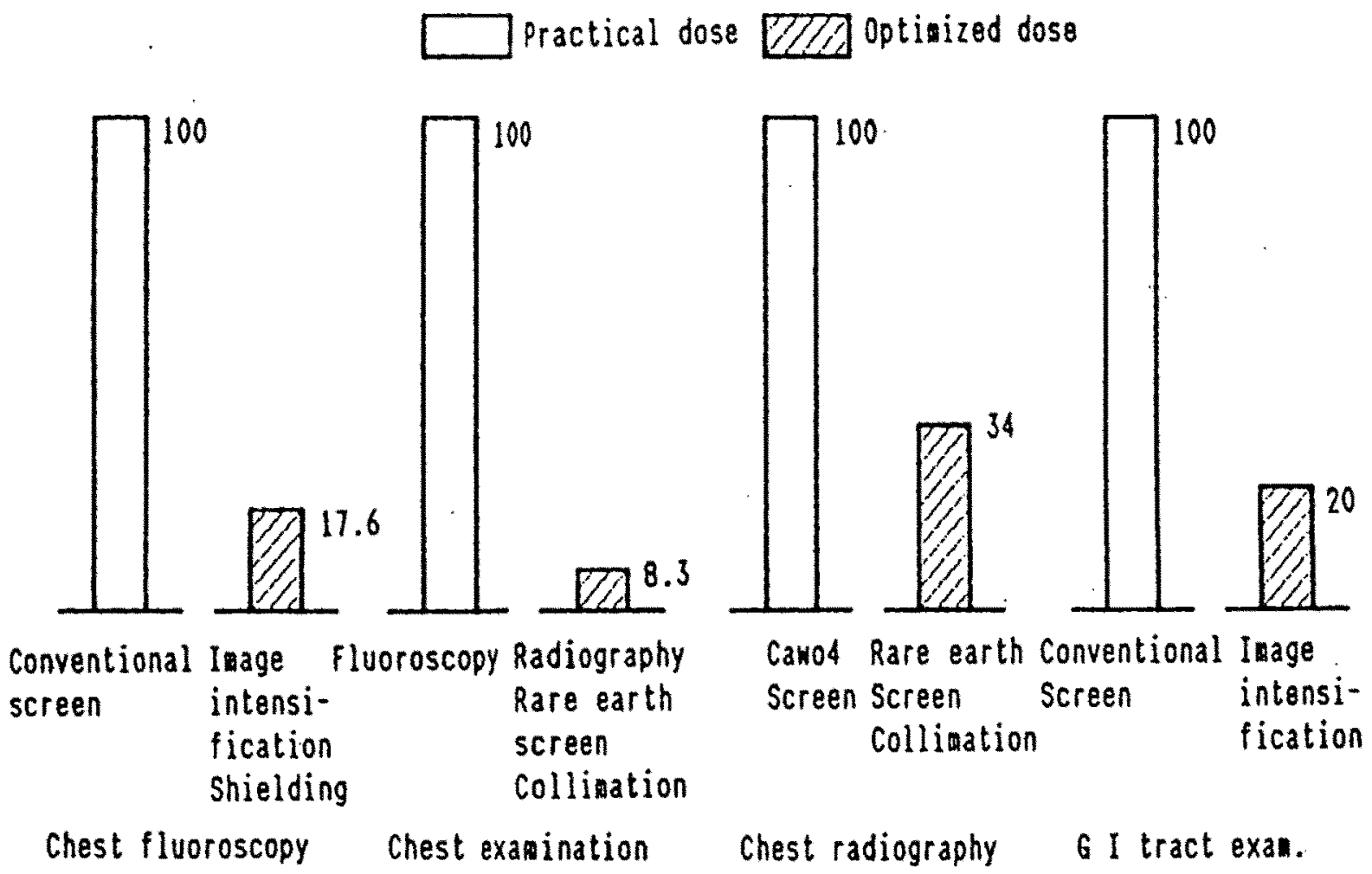

Fig. 4 - Effect of various optimization measures.

Effet de diverses opérations d'optimisation.

\section{Optimization analysis}

Notwithstanding that the foregoing results have demonstrated marked reduction of patient doses by taking appropriate measures, the following questions may yet be raised : is the additional cost of protective measures taken worthwhile as compared with the reduced detriment to patient's health ? Which is the best one among various protective measures ? To answer these questions, an optimization analysis of feasible protective measures was conducted.

As recommended by ICRP Publication 37 [2], - $\Delta x / \Delta s$ (the actual cost of protection for reducing $1 \mathrm{man} \cdot \mathrm{Sv}$ of patient collective dose in protection practice) was compared with the value of $\alpha$ factor. As the competent authority in China has not yet determined the appropriate $\alpha$ value, the minimum limit of $\alpha$ value recommended by IAEA [3] was adopted as reference value in the costbenefit analysis, i.e. $\alpha_{\min }=\mathrm{US} \$ 3000 / \mathrm{man} \cdot \mathrm{Sv}$. The example of the cost-benefit analysis is given below.

(1) Cost-benefit analysis of simple shielding in chest fluoroscopy. The following assumptions were made according to the actual conditions in China :

- lead rubber apron of $0.5 \mathrm{~mm}$ lead equivalent is used in chest fluoroscopy and radiography to protect abdomen and gonads from irradiation; lead rubber neckband is used to protect thyroid gland; 
- the prices of lead apron and lead neckband are 50 and 10 US \$/piece, respectively and their service life is 10 years ;

- there are 300 working days. in a year, and 10 patients for chest fluoroscopy and 2 patients for chest radiography are examined in a working day.

(2) Cost-benefit analysis of simple shielding in chest radiography; same assumptions except that the working load for chest radiography is 2 patients in a working day.

(3) Optimization analysis of replacing calcium tungstate screen with rare earth screen in chest radiography ; assumptions :

- the prices of rare earth screen $[\mathrm{BaFCl}(\mathrm{Eu})]$ and calcium tungstate screen are 40 and 20 US \$/piece respectively, and their service life is 2 years;

- there are 300 working days a year and two patients are examined in a working day.

(4) Optimization analysis of replacing conventional fluoroscopic screen by image intensifier in GI tract examination ; assumptions :

- the price of the image intensifier (not including $X$-ray machine) is 30,000 US $\$$ piece, and its service life is 10 years ;

- there are 300 working days in a year, and 2 patients undergo GI examination in a working day.

(5) Optimization analysis of replacing conventional fluoroscopic screen by image intensifier in chest fluoroscopy ; same assumptions as for GI examination except that the working load for chest fluoroscopy is 20 patients in a working day.

Based on the above assumptions and patient doses given in Table III and the dose reduction coefficients given in Table $\mathrm{V}$, optimization analysis was made as shown in Table VI.

The conclusions drawn from the analysis in Table VI are :

- the costs of reducing 1 man $\cdot S v$ in (1), (2), (3) and (4) are lower than the assigned $\alpha$ value ; hence, the measures taken are consistent with the principle of optimization ;

- the cost of reducing $1 \mathrm{man} \cdot \mathrm{Sv}$ in (5) is roughly equivalent to the $\alpha$ value. It suggests that when the working load per day for chest fluoroscopy is greater than 20 patients, the $-\Delta x / \Delta s$ value is lower than the $\alpha$ value, and the measure taken is in conformity with the principle of optimization; and when the working load is smaller than 20 patients, the $-\Delta x / \Delta s$ value is greater than the $\alpha$ value, and the measure does not fit with the principle of optimization.

\section{Objective dose}

In diagnostic radiology, the exposure dose to the patient should, first of all, meet the requirements of obtaining sufficient diagnostic information, not complying with a predetermined limit; therefore, the individual dose limit does not apply. Nevertheless, as suggested by ICRP Publication 60 [3], proper constraints of patient dose should be considered. Consequently, it is logical to derive a particular limit from this constraint. The authors believe that this par- 
TABLE VI

Optimization analysis for some $X$-ray examination in diagnostic radiology Analyse d'optimisation pour quelques examens de radiodiagnostic aux rayons $X$

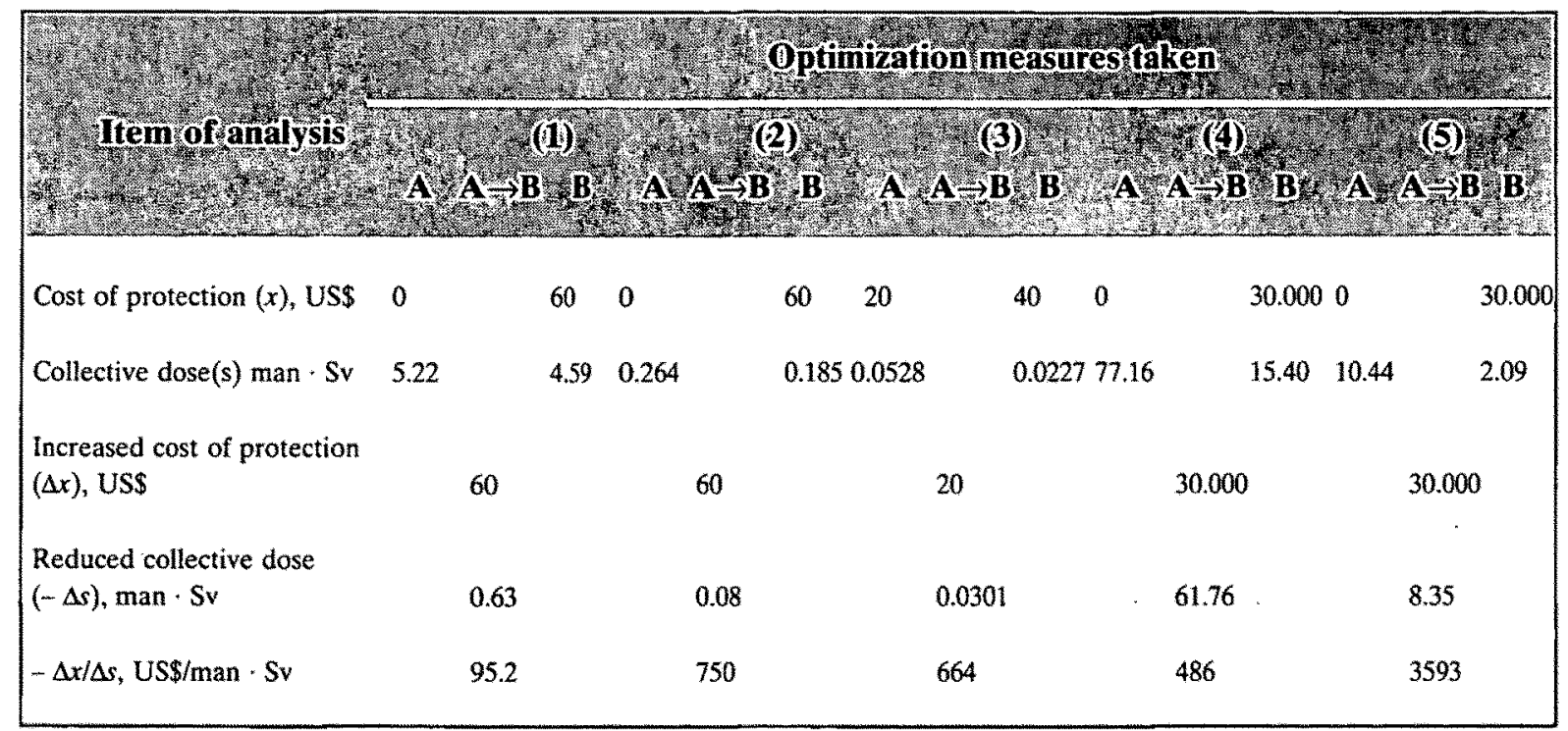

Note : A : without optimization ; B : with optimization.

ticular limit should be achievable in practice, and the protective measures to attain this objective should conform with the principle of optimization. On this basis, the particular limits of patient doses from various radiological procedures can be established. These limits can be applied with flexibility, allowing provisional non-compliance by medical institutions with substandard equipment.

Considering the above conditions, the authors designated the particular limit of patient dose as objective dose (equivalent to dose constraints or investigation levels in ICRP Publication 60), implying the objective to be reached by medical institutions in improving radiation protection. The value of the objective dose is the product of the practical dose for certain X-ray examination and the dose reduction coefficient for corresponding optimization measure. Objective doses for several X-ray procedures are recommended (Tab. VII).

TABLE VII

Objective doses for several $X$-ray procedures Dose objective pour plusieurs examens aux rayons $X$

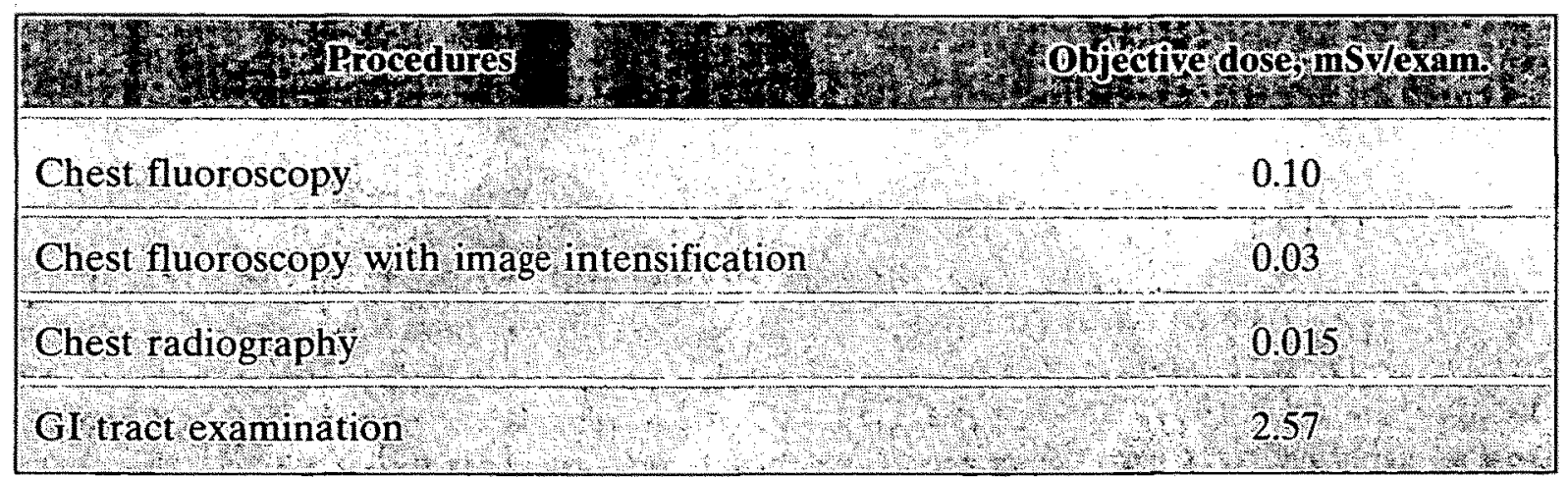




\section{Conclusion}

For optimization purpose, in this research project the investigated patient doses were classified into practical dose, justified dose and optimized dose so as to evaluate the effects of managerial and equipment factors on patient doses separately.

The results show that patient doses in chest fluoroscopy and chest radiography can be reduced by $40 \%$ and $18 \%$ respectively if only standard X-ray procedures are strictly followed and quality control of equipment is maintained without radical alteration of existing equipment.

In order to reveal the effect of equipment factor on patient doses, we took various measures to improve the equipment (Fig. 4), and evaluated their effectiveness in reducing patient doses. The results show that in chest radiography the use of rare earth screen instead of $\mathrm{CaOW}_{4}$ screen, combined with beam limitation, can reduce the patient dose by $66 \%$; in GI examination the use of image intensifier instead of conventional fluoroscopic screen can reduce the patient dose by $80 \%$; and the use of chest radiography instead of chest fluoroscopy, combined with rare earth screen and beam limitation, can reduce the patient dose by over $91.7 \%$. Optimization analysis indicates that the above measures of equipment improvement fit with the principle of optimization.

Most of the measures mentioned above can reduce patient doses markedly with lower costs and easily wide application. Adoption of these measures should bring good economic and social benefit. But the application of certain measure depends on practical circumstances. For example, chest fluoroscopy procedure has been discarded in developed countries since it results in patient doses as high as 3-6 times those from chest radiography and poor quality of image. In China, however, there are as many as some 12000 small-capacity Xray machines ( 30 and $50 \mathrm{~mA}$ ), which are suitable only for fluoroscopy and not for chest radiography. Their total replacement is impossible within a short delay due to financial problems. Besides, there are some difficulties with film supply in China. Therefore, the procedure of chest fluoroscopy has to continue for some time for a number of hospitals in China. Consequently, we also investigated the protection of patient in chest fluoroscopy and made optimization analysis. The purpose is dual : to indicate how to improve this 'X-ray procedure, and to demonstrate the effective ways to improve protection and to reduce patient doses as much as possible as long as this procedure is still used.

\section{Acknowledgements}

This study was supported by the International atomic energy agency (IAEA) under contracts $n^{\circ} 4965 / R 0 / R B$ and 4965/R1/RB.

Many people have made a great contribution to this study : Den Daping, Sun Zuozhong, Yang Yingxiao, Wang Yannan, Li Quantai, Hou.Jinpeng (Institute of radiation medicine, Shandong academy of medical sciences) ; Du Guangheng, Jiang Rende, Tian Kaizhen, Wei Quan (Sichuan institute of radiation health protection); Zhang Yuping, Chen Jindi, Li Wenhong, Yao Jiaxiang (Laboratory of industrial hygiene, ministry of public health). 


\section{REFERENCES}

[1] INTERNATIONAL ATOMIC ENERGY AGENCY (IAEA) - Assigning a value to transboundary radiation exposure. (Safety Series $n^{\circ} 67$ ). Vienna : IAEA, 1985.

[2] INTERNATIONAL COMMISSION ON RADIOLOGICAL PROTECTION (ICRP) - Cost-benefit analysis in the optimization of radiation protection (ICRP Publication 37). Ann ICRP, 1983, 10 (2/3).

[3] INTERNATIONAL COMMISSION ON RADIOLOGICAL PROTECTION (ICRP) - 1990 Recommendations (ICRP Publication 60). Ann ICRP, 1991, 21 (1/3).

[4] JIA D. et al. - Patient doses from chest fluoroscopy in Beijing. Radiation Protection, 1987, 7 (5), 341 (in Chinese).

[5] SU X. et al. - Study on protection measures for patients in X-ray diagnosis. In : Selected papers on protection in diagnostic radiology. Sanitary epidemiological section, Bureau of public health, Shandong province, 1984 (in Chinese). 